\title{
DOS CUESTIONES PREJUDICIALES SOBRE LA PRESCRIPCIÓN DE LA ACCIÓN DE RESTITUCIÓN DE LOS GASTOS HIPOTECARIOS Y SUS EFECTOS EN EL CRÉDITO REVOLVING USURARIO*
}

\author{
Manuel Jesús Marín López** \\ Catedrático de Derecho Civil \\ Centro de Estudios de Consumo \\ Universidad de Castilla-La Mancha
}

Title: Two preliminary rulings on the prescription of the action for restitution of mortgage expenses and its effects on the usurious revolving credit

Resumen: El Tribunal Supremo y el Juzgado de Primera Instancia no 20 de Barcelona han planteado dos cuestiones prejudiciales al TJUE (ambas por auto de 22 de julio de 2021) sobre el comienzo del plazo de prescripción (dies a quo) de la acción de restitución de las cantidades abonadas por el consumidor como consecuencia de una cláusula nula sobre gastos hipotecarios. En este trabajo se examinan estas dos cuestiones prejudiciales, y en particular, la afirmación contenida en la primera de ellas acerca de que sí prescribe la acción de restitución de cantidades tras la nulidad del contrato o de una cláusula abusiva. Se estudia también la aplicación de esta regla al crédito revolving usurario, con los efectos que ello provoca: la imposibilidad de seguir manteniendo (como hacen algunos tribunales) que no prescribe la acción de restitución de los intereses usurarios abonados.

\footnotetext{
* Trabajo realizado en el marco del Proyecto de Investigación PGC2018-098683-B-I00, del Ministerio de Ciencia, Innovación y Universidades (MCIU) y la Agencia Estatal de Investigación (AEI) cofinanciado por el Fondo Europeo de Desarrollo Regional (FEDER) titulado "Protección de consumidores y riesgo de exclusión social" dirigido por Ángel Carrasco Perera y Encarna Cordero Lobato; de la Ayuda para la realización de proyectos de investigación científica y transferencia de tecnología, de la Junta de Comunidades de Castilla-La Mancha cofinanciadas por el Fondo Europeo de Desarrollo Regional (FEDER) para el Proyecto titulado "Protección de consumidores y riesgo de exclusión social en CastillaLa Mancha" (PCRECLM) con Ref.: SBPLY/19/180501/000333 dirigido por Ángel Carrasco Perera y Ana Isabel Mendoza Losana y a la Ayuda para la financiación de actividades de investigación dirigidas a grupos de la UCLM Ref.: 2021-GRIN-31309, denominado "Grupo de Investigación del Profesor Ángel Carrasco" (GIPAC). ** ORCID ID: https://orcid.org/0000-0001-9645-6325
} 
Palabras clave: Cláusulas de gastos; crédito revolving; usura; acción de restitución; prescripción; dies a quo del plazo de prescripción.

\begin{abstract}
The Supreme Court and the Court of First Instance No. 20 of Barcelona have submitted two preliminary questions to the CJEU (both by order of July 22, 2021) on the beginning of the limitation period (dies a quo) of the action for restitution of the amounts paid by the consumer as a result of a null clause on mortgage expenses. This paper examines these two preliminary questions, and in particular, the statement contained in the first of them that it does prescribe the action for restitution of amounts after the nullity of the contract or an abusive clause. The application of this rule to usurious revolving credit is also studied, with the effects that this causes: the impossibility of continuing to maintain (as some courts do) that does not prescribe the action of restitution of the usurious interests paid.
\end{abstract}

Key words: Expense terms; revolving credit; usury; restitution action; prescription; dies a quo of the limitation period.

SUMARIO: I. Introducción. II. Las dos cuestiones prejudiciales sobre el inicio del plazo de prescripción de la acción de restitución de cantidades tras la nulidad de la cláusula de gastos. 1. La cuestión prejudicial planteada por el Tribunal Supremo por auto de 22 de julio de 2021. 2. La cuestión prejudicial planteada por el Juzgado de Primera Instancia no 20 de Barcelona por auto de 22 de julio de 2021. III. El Tribunal Supremo sanciona que la acción de restitución de prestaciones sí prescribe. 1. Doctrina clásica del Tribunal Supremo sobre la prescripción de la acción de restitución. 2. Doctrina del Tribunal Supremo en el auto de 22 de julio de 2021 sobre el carácter prescriptible de la acción de restitución de prestaciones. 3. La compatibilidad de la prescriptibilidad de la acción de restitución con la jurisprudencia del TJUE. 4. La aplicación de la doctrina al crédito revolving usurario: la imposibilidad de seguir manteniendo que no prescribe la acción de restitución de los intereses usurarios abonados. IV. El "dies a quo" de la acción de restitución de los gastos hipotecarios en las cuestiones prejudiciales. V. Intrascendencia de las cuestiones prejudiciales para fijar el "dies a quo" de la acción de restitución de cantidades en el crédito revolving nulo.

\title{
I. Planteamiento
}

Hoy es una cuestión incontrovertida el carácter abusivo de la cláusula del contrato de préstamo hipotecario que impone al prestatario el abono de todos los gastos de constitución del préstamo. También es pacífica la jurisprudencia del TS que establece qué efectos provoca la nulidad de la cláusula de gastos y que, en particular, permite al prestatario reclamar la devolución íntegra de las cantidades abonadas en concepto de gestoría, tasación e inscripción de la hipoteca en el Registro de la Propiedad, y la 
restitución de la mitad de los gastos de notaría (al margen de las copias, que debe abonarlas el contratante que las solicitó) ${ }^{1}$.

Pero en relación con la cláusula de gastos existen todavía aspectos discutibles. La cuestión más debatida es, sin duda, la relativa al dies a quo del plazo de prescripción de la acción de restitución de cantidades que surge tras la nulidad de la cláusula. Hay que determinar si la acción de restitución de cantidades prescribe o no, y en caso positivo, cuál es el plazo de prescripción y qué día empieza a correr este plazo. La doctrina científica ha defendido distintos criterios, y hasta la fecha el Tribunal Supremo no ha dictado una sentencia que unifique las distintas interpretaciones defendidas por las Audiencias Provinciales. La inexistencia de una posición definida de nuestro alto Tribunal provoca una enorme inseguridad jurídica $y$, con ello, un aumento de la litigiosidad. Pues el consumidor (y su abogado) no saben si la reclamación judicial resultará exitosa, aun habiendo transcurrido 15 o 20 años desde la celebración del préstamo hipotecario; y por eso se animan a demandar.

El Tribunal de Justicia de la Unión Europea ha tenido la oportunidad de pronunciarse en varias ocasiones sobre la posible contrariedad a la normativa europea de la ley nacional que establece un plazo de prescripción para la acción restitutoria. Estas sentencias del TJUE no son de fácil interpretación, y por ello las Audiencias Provinciales han seguido defendiendo criterios diferentes sobre el dies a quo del plazo de prescripción de esta acción.

Para tratar de aclarar definitivamente la cuestión, el Tribunal Supremo ha planteado cuestión prejudicial mediante auto de 22 de julio de 2021 (ECLI:ES:TS:2021:10157A). De esa misma fecha es el auto del Juzgado de Primera Instancia no 20 de Barcelona que igualmente plantea cuestión prejudicial sobre el comienzo del plazo de prescripción de la acción de restitución de las cantidades pagadas por el consumidor como consecuencia de una cláusula nula sobre gastos hipotecarios (ECLI:ES:JPI:2021:297A). Estas dos cuestiones prejudiciales, que presumiblemente serán resueltas por el TJUE de manera conjunta, deben servir para poner fin a esta larga historia y zanjar definitivamente la controversia. Repárese que la sentencia que en su momento dicte el TJUE no servirá únicamente para la cláusula de gastos, sino que será aplicable a cualquier acción de restitución de cantidades derivada de la nulidad de una cláusula abusiva.

Este trabajo tiene por objeto analizar las dos cuestiones prejudiciales mencionadas y sus consecuencias en el crédito revolving usurario. A estos efectos se examinan las concretas preguntas que se formulan en cada una de ellas, y también los argumentos que utilizan los órganos judiciales que las plantean. En este sentido, el auto del Tribunal Supremo contiene una serie de reflexiones que evidencian cuál es su opinión sobre algunos de los puntos más importantes de esta materia. Así, por ejemplo,

\footnotetext{
${ }^{1}$ Sobre el particular, mi trabajo "Cuestiones pendientes sobre la cláusula de gastos de los préstamos hipotecarios", en ÁLVAREZ LATA/PEÑA LÓPEZ, Mecanismos de protección del consumidor de productos y servicios financieros, Cizur Menor, Thomson Reuters, 2021, pp. 141 y ss.
} 
señala que la acción de restitución de cantidades sí está sometida a un plazo de prescripción, y que ese plazo es el contenido en el art. 1964 CC. También se estudia en estas líneas la oportunidad de las preguntas formuladas en las cuestiones prejudiciales sobre el dies a quo del plazo de prescripción de la acción de restitución. Pero la finalidad última de este trabajo es comprobar de qué modo las cuestiones prejudiciales han de afectar a la acción de restitución de cantidades que deriva de la nulidad de un crédito revolving usurario.

\section{Las dos cuestiones prejudiciales sobre el inicio del plazo de prescripción de la acción de restitución de cantidades tras la nulidad de la cláusula de gastos}

\section{La cuestión prejudicial planteada por el Tribunal Supremo por auto de 22 de julio de 2021}

El Tribunal Supremo ha planteado una cuestión prejudicial mediante auto de 22 de julio de 2021 (ECLI:ES:TS:2021:10157A), del que es ponente el Excmo. Sr. D. Pedro José Vela Torres. Esta cuestión se plantea en el marco del recurso de casación 1799/2020, interpuesto por los prestatarios consumidores contra la SAP Barcelona 20/2020, de 8 de enero de 2020 (ECLI:ES:APB:2020:24), dictada por la Sección 15a en el recurso de apelación 592/2019. La Audiencia Provincial considera prescrita la acción de restitución de cantidades. Considera que el día inicial del cómputo del plazo de prescripción de la acción de restitución era el día en que los consumidores habían abonado los gastos, lo que ocurrió en 1999. Cuando en 2017 los consumidores interponen la demanda ya ha transcurrido el plazo de prescripción (que es de diez años en el derecho catalán), por lo que la acción restitutoria ha de reputarse prescrita.

La cuestión prejudicial se estructura del siguiente modo. Tras exponer los antecedentes del litigio (FJ $1^{\circ}$ ), se indica cuál es la cuestión controvertida (Fundamento de Derecho $2^{\circ}$ ): determinar cuándo comienza el plazo de prescripción de la acción de restitución de las cantidades pagadas por el consumidor a un tercero como consecuencia de una cláusula abusiva que impone al prestatario el pago de todos los gastos generados por la concertación de un préstamo hipotecario. Después se enumeran las disposiciones del Derecho de la Unión y del derecho nacional que resultan aplicables (FJ $3^{\circ}$ y 4 ).

Las dos partes más interesantes de la cuestión prejudicial se incluyen en los Fundamentos de Derecho $4^{\circ}$ y $5^{\circ}$. En el primero, después de enumerar las normas aplicables del derecho español, el Tribunal Supremo expone su doctrina sobre la acción declarativa de nulidad de un contrato (que es imprescriptible) y la acción de restitución de las prestaciones ejecutadas, que sí prescribe y está sometida al plazo de prescripción del art. 1964 CC. El Tribunal Supremo entiende que estas reglas son aplicables a la acción de restitución de cantidades que surge tras la nulidad de una 
cláusula abusiva, que a su juicio es una acción derivada de un cobro de lo indebido (art. 1896 CC).

Por su parte, el Fundamento de Derecho $5^{\circ}$ expone las razones por las que resulta necesario plantear la cuestión prejudicial. El auto recoge la jurisprudencia del TJUE sobre prescripción de las acciones de restitución de cantidades tras la nulidad de una cláusula, y establece que, según esta jurisprudencia, no es compatible con la Directiva 93/13/CE fijar el comienzo del cómputo del plazo prescriptivo en la fecha en que se celebra el contrato, se realiza el pago o se cumple íntegramente el contrato. Por ello, entiende que el día inicial del plazo no puede ser aquel en que se abonaron los gastos indebidos. Así que quedan dos opciones: o fijar como dies a quo la fecha de la sentencia que declara la nulidad de la cláusula, o reputar como tal el día en que el Tribunal Supremo dicta las sentencias que dicen cómo deben distribuirse los gastos entre prestamista y prestatario o aquél en que el TJUE admite que la acción de restitución puede estar sujeta a un plazo de prescripción. La primera opción puede colisionar con el principio de seguridad jurídica, al convertir en la práctica la acción de restitución en imprescriptible. La segunda opción, en cambio, puede no respetar el principio de efectividad, por ser dudoso que un consumidor medio, razonablemente atento y perspicaz pueda conocer la jurisprudencia del Tribunal Supremo o del TJUE en la materia.

A la vista de lo expuesto, el auto plantea las tres preguntas siguientes:

"1.- ¿Es conforme con el principio de seguridad jurídica interpretar los artículos 6.1 y 7.1 de la Directiva 93/13/CEE del Consejo, de 5 de abril de 1993, sobre cláusulas abusivas en los contratos con consumidores, en el sentido de que el plazo de prescripción de la acción para reclamar lo pagado en virtud de una cláusula abusiva no comienza a correr hasta que por sentencia firme se haya declarado la nulidad de dicha cláusula?

2.- Si tal interpretación no fuera conforme con el principio de seguridad jurídica, ¿se opone a los mencionados artículos de la referida Directiva una interpretación que considere día inicial del plazo de prescripción la fecha de las sentencias del Tribunal Supremo que fijaron doctrina jurisprudencial sobre los efectos restitutorios (sentencias de 23 de enero de 2019)?

3.- Si tal interpretación se opusiera a los referidos artículos, ¿se opone a los mismos una interpretación que considere día inicial del plazo de prescripción la fecha de las sentencias del Tribunal de Justicia que declararon que la acción de restitución podía estar sujeta a un plazo de prescripción (básicamente, SSTJUE de 9 de julio de 2020, Raiffeisen Bank SA, asuntos acumulados C-698/10 y 699/18; o de 16 de julio de 2020, Caixabank SA, asuntos acumulados C-224/19 y C- 259/19, que confirma la anterior?" 


\section{La cuestión prejudicial planteada por el Juzgado de Primera Instancia no 20 de Barcelona por auto de 22 de julio de 2021}

El Juzgado de Primera Instancia no 20 de Barcelona (Magistrada-Juez: Dña. Rocío Ortega Atienza) ha interpuesto una cuestión prejudicial sobre el dies a quo del plazo de prescripción de la acción de restitución de los gastos hipotecarios. Lo hace mediante auto de 22 de julio de 2021 (ECLI:ES:JPI:2021:297A), precisamente el mismo día del auto en el que el Tribunal Supremo plantea su cuestión prejudicial. En el caso de autos el préstamo hipotecario se había concertado en el año 2007. En mayo de 2019 el consumidor prestatario interpuso demanda en la que solicitaba que se declara la nulidad de la cláusula de gastos y se condenara a la devolución de los aranceles notariales. En febrero de 2021 interpone una segunda demanda en la que pide la restitución de los aranceles registrales y gastos de gestoría. Es en el marco de esta segunda demanda en el que el JPI no 20 de Barcelona plantea la cuestión prejudicial.

Según el auto de planteamiento de la cuestión prejudicial, el núcleo de la controversia es conocer si el actor, un consumidor que ha contratado con una entidad bancaria, puede verse privado de reclamar las cantidades fruto de una cláusula abusiva porque el plazo de prescripción de su acción comienza antes de que la cláusula sea declarada nula (apartado 7 del auto).

El auto señala cómo esta cuestión se ha resuelto de manera diferente en las distintas Audiencias Provinciales catalanas (ap. 11 a 14). Así, la AP Barcelona sostiene que el plazo de prescripción se inicia cuando se abona la factura de los gastos, pues en ese momento se agotan los efectos de la cláusula y ya no hay riesgo de que se pueda extender el perjuicio al consumidor durante la ejecución del contrato. Para la AP Tarragona, el dies a quo es la STS de 23 de diciembre de 2015. Esta es la tesis defendida también por la AP Gerona. En cambio, la AP Lérida entiende que el plazo prescriptivo se inicia cuando se declara por sentencia la nulidad de la cláusula.

Después de analizar el principio de efectividad del derecho de la Unión Europea, y de su relevancia a los efectos de fijar el dies a quo del plazo de prescripción (ap. 18), el auto acude al art. 121-23 del Código Civil catalán, que fija como inicio del plazo de prescripción la fecha en que el titular de la pretensión "conoce o puede conocer razonablemente las circunstancias que la fundamentan" (ap. 19). En el caso de autos es relevante el hecho de que los efectos de la cláusula de gastos se agotan tras su abono, al principio del contrato, de modo que no hay riesgo alguno de que se pueda volver a aplicar esa cláusula durante la vigencia del contrato.

Ante esta circunstancia se plantea cuándo el consumidor puede tener conocimiento de los hechos en que fundamenta la acción de reclamación de cantidad: si es cuando realiza los pagos y agota el contenido de la cláusula; si es cuando se dicta la sentencia que declara la nulidad o si es cuando los tribunales empiezan a declarar la nulidad de una cláusula como la suya, siendo relevante la sentencia del Tribunal Supremo de 23 
de diciembre de 2015 que sienta jurisprudencia sobre esta materia. En opinión de la Magistrada, no hay duda alguna que los artículos 6.1 y 7.1 de la Directiva 13/93 se respetan $y$, por tanto, se garantiza el principio de efectividad del derecho comunitario, si se fija el inicio de la prescripción en el momento de la declaración de nulidad, pero es más dudoso entender que se respeta este principio si los efectos de cláusula se han agotado mucho antes sin riesgo alguno de repetición o si el conocimiento de la posibilidad de ejercer la acción se sujeta al dictado de una sentencia del Tribunal Supremo que el consumidor puede no conocer hasta tiempo después (ap. 21).

En opinión de la juzgadora, las sentencias del TJUE que han analizado el inicio del plazo de prescripción lo han hecho respecto de cláusula que se seguían aplicando y que, por tanto, no habían cesado de producir efectos. Lo que no sucede en la cláusula de gastos, cuyos efectos se producen en su totalidad tras el abono de los gastos, justo después de la celebración del contrato (ap. 23). En efecto, la STJUE de 10 de junio de 2021, que considera contrario al derecho comunitario que la prescripción se inicie en el momento de la firma de la oferta, analiza una cláusula que estará vigente durante toda la duración del contrato. En el mismo sentido, la STJUE de 22 de abril de 2021, que entiende contrario al derecho comunitario iniciar el cómputo cuando se produce el enriquecimiento del empresario, trataba de una cláusula que potencialmente se podía volver a aplicar. Por otro lado, señala el auto que no se han establecido criterios claros sobre qué elementos hay que valorar para analizar cuando el consumidor tiene conocimiento de que una cláusula es abusiva y, por tanto, se inicia el cómputo de la prescripción de la acción para reclamar la restitución de las cantidades abonadas.

Por todo ello, el auto formula tres preguntas:

"Primera: Si es compatible con el artículo 38 CDFUE, con el princ1p10 de efectividad del derecho de la UE y con los artículos 6.1 y 7.1 de la Directiva 13/93 que la prescripción de la acción para reclamar las consecuencias económicas de una cláusula abusiva, como la de gastos, se inicie con anterioridad al momento en que dicha cláusula ha sido declarada nula por abusiva.

Segunda: Si es compatible con el artículo 38 CDFUE, con el princ1p10 de efectividad del derecho de la UE y con los artículos 6.1 y 7.1 de la Directiva 13/93 fijar como inicio del plazo de prescripción de una cláusula abusiva la fecha en que un Tribunal con capacidad de crear jurisprudencia, como es el Tribunal Supremo, indique que una determinada cláusula es abusiva con independencia de que el consumidor concreto conozca o no el contenido de esa sentencia.

Tercera: Si es compatible con el artículo 38 CDFUE, con el princ1p10 de efectividad del derecho de la UE y con los artículos 6.1 y 7.1 de la Directiva 13/93 fijar, en un contrato de larga duración, que el plazo de prescripción de una acción para reclamar unos gastos pagados para constituir la hipoteca se inicie en el 
momento en que se hace el pago dado que la cláusula abusiva ha agotado sus efectos en ese momento y no hay riesgo de que la cláusula se vuelva a aplicar"

\section{El Tribunal Supremo sanciona que la acción de restitución de prestaciones sí prescribe}

De las dos cuestiones prejudiciales resulta especialmente interesante las reflexiones que se contienen en una de ellas (la planteada por el Tribunal Supremo) relativas a si la acción de devolución de cantidades está sometida (o no) a plazo de prescripción. Es Ilamativo que la cuestión prejudicial del Juzgado de Barcelona ni siquiera se pronuncie sobre esta materia, pues parte de la premisa (que acepta como indiscutible) de que la acción de restitución sí está sometida a un plazo de prescripción, que en el derecho catalán es de diez años, según el art. 121-20 del Código Civil catalán.

\section{Doctrina clásica del Tribunal Supremo sobre la prescripción de la acción de restitución}

La forma correcta de afrontar el debate acerca de la prescripción de la acción es distinguir entre la acción declarativa de nulidad y la acción de restitución de cantidades.

Antes del auto de planteamiento de la cuestión prejudicial, el Tribunal Supremo ha establecido, en una jurisprudencia que ha de reputarse consolidada, que en los casos de nulidad absoluta o radical la acción declarativa de nulidad no está sometida a plazo de prescripción. Se trata, pues, de una acción imprescriptible. En esta línea, pueden citarse las SSTS de 13 de febrero de 1985 (RJ 810), 23 de octubre de 1992 (RJ 8279), 21 de enero de 2003 (RJ 563), 6 de septiembre de 2006 (RJ 8008), 30 diciembre 2010 (RJ 2011, 1791), 25 de marzo de 2013 (RJ 4596), 24 de abril de 2013 (RJ 3692), 6 de octubre de 2016 (RJ 4756), 6 de febrero de 2020 (RJ 181), 85/2020, de 6 de febrero (181). Ejemplo paradigmático de esta tesis es la STS de 19 de noviembre de 2015 (RJ 5501), que establece que "ante la absoluta falta de consentimiento por parte del cliente, debe declararse radicalmente nulo el contrato de comercialización o adquisición de obligaciones subordinadas. Sin que tampoco sea atendible el argumento de la parte demandada relativo a la caducidad de la acción, puesto que tratándose de nulidad absoluta, la acción es imprescriptible (por todas, Sentencia de esta Sala 178/2013, de 25 de marzo".

La acción declarativa de nulidad no prescribe nunca, al margen de cuál sea la causa que provoca esa nulidad absoluta. A estos efectos, es indiferente si la nulidad absoluta se produce por la ausencia de alguno de los elementos esenciales del contrato (consentimiento, objeto o causa), por no existir la cosa objeto del contrato en el momento de su celebración (arg. art. 1460.I CC), por ser el objeto o la causa 
ilícita (art. $1.275 \mathrm{CC}$ ) o por contravenir una norma imperativa o prohibitiva (art. 6.3 $\mathrm{CC}$ ). También son nulas (nulidad absoluta) las cláusulas predispuestas abusivas incluidas en contratos con consumidores (art. 83 TRLGDCU). Como la nulidad del préstamo usurario es una nulidad absoluta, tampoco prescribe la acción declarativa de nulidad en ese caso, como acertadamente señalan las SSTS 539/2009, de 14 de julio (RJ 4467), y 628/2015, de 15 de noviembre (RJ 5001), al afirmar que la nulidad del préstamo usurario "no es susceptible de prescripción extintiva".

Por otra parte, como las cláusulas abusivas incluidas en contratos con consumidores son nulas de pleno derecho (art. 83 TRLGDCU), la acción para obtener una sentencia que declare la nulidad de esa cláusula es imprescriptible. Así lo ha establecido el TJUE. Las SSTJUE de 9 de julio de 2020 (asuntos C-698/18 y C-699/18) y 16 de julio de 2020 (asuntos C-224/19 y C-259/19) han declarado que es contraria a la Directiva 93/13/CEE, de cláusulas abusivas, una norma nacional que prohíba al juez nacional, al expirar un plazo de preclusión, declarar el carácter abusivo de una cláusula predispuesta. En el mismo sentido se expresa la STJUE de 10 de junio de 2021 (asuntos C-776/19 a C-782/19), según la cual "para garantizar una protección efectiva de los derechos que la Directiva 93/13 confiere al consumidor, este debe poder invocar en todo momento el carácter abusivo de una cláusula contractual no solo como medio de defensa, sino también a efectos de que el juez declare el carácter abusivo de una cláusula contractual, de modo que una acción ejercitada por el consumidor para que se declare el carácter abusivo de una cláusula incluida en un contrato celebrado entre un profesional y un consumidor no puede estar sujeta a ningún plazo de prescripción" (ap. 38).

En realidad, la acción de declaración de la nulidad es imprescriptible no solo en los casos de nulidad radical o absoluta, sino también en los de nulidad relativa o anulabilidad. Por eso, si es el demandado el que vía excepción alega la nulidad relativa del contrato (por ejemplo, por violencia, dolo o error), podrá hacerlo aunque hayan transcurrido cuatro años, pues no solicita restitución alguna.

En cuanto a la acción de restitución de las prestaciones ejecutadas, que es la obligación liquidatoria que impone a las partes el art. 1303 CC, el Tribunal Supremo carece de una jurisprudencia consolidada.

Hay un primer grupo de sentencias que defienden que la acción de restitución sí prescribe. En este sentido se pronuncia la STS de 27 de febrero de 1964 (RJ 1152), con cita de la STS de 10 de abril de 1947 (RJ 401). Esta sentencia dispone que "dentro de nuestro Código Civil, la cuestión aparece clara: en el párr. $2^{\circ}$ del art. 1930, se declara la prescriptibilidad de los "derechos y acciones, de cualquier clase que sean"; en los arts. 1295 y 1306, respectivamente, se establecen las obligaciones de las partes, en orden a deshacer los efectos de los contratos rescindidos o nulos por concurrencia de causa, torpe, sin establecer que, las oportunas acciones restitutorias sean imprescriptibles, cuyo carácter reconoce el Código sólo a las que enumera en su art. 1965; de aquí se sigue que aun no participando de la opinión de 
la Sala sentenciadora en orden a la inexistencia de la radical nulidad que se invoca y dicho queda que este Tribunal la estima acertada- no escaparían las consecuencias fácticas, ya producidas y aun reiteradas por las partes en anteriores litigios, a la eficacia de la prescripción, cuya excepción alegada y aceptada en la instancia, por todo lo dicho, no puede quedar sin efecto, a la vista de los preceptos legales cuya infundada infracción, el recurrente denuncia".

En este mismo sentido se expresa la STS de 30 de diciembre de 2010 (RJ 2011, 1791), en el caso "Havana Club". Tras declarar imprescriptible la acción declarativa de nulidad de la inscripción registral en el registro de marcas, sostiene que "no sucede, sin embargo, lo propio con la que hemos calificado como acción restitutoria "sui generis" de la marca número 99.789, pues, siendo la misma puramente personal, como se indicó, y encerrando propiamente una pretensión de condena, su prescripción extintiva estaba sujeta al plazo de quince años que establece, para las de esa clase que no tengan señalado uno especial, el artículo 1.964 del Código Civil" (FJ 14a).

Pero el propio Tribunal Supremo también ha defendido la imprescriptibilidad de la acción de restitución. Así sucede en la STS de 25 de marzo de 2013 (RJ 4596). Se trata de un supuesto de enajenación de acción simulado. No es cuestión debatida que la acción declarativa de simulación no prescribe, pero sí el régimen de prescripción de la restitución. Y el Tribunal Supremo establece que esta acción no prescribe. Lo hace de este modo: "en este caso, en el que es ficticia la propia titularidad resultante del acuerdo de simulación, la restitución de los bienes está sometida al mismo régimen de imprescriptibilidad que la acción declarativa de la simulación, por cuanto nada deriva de la nada -"ex nihilo nihil"-". En todo caso, la tesis de la imprescriptibilidad de la acción de restitución ya no puede sostenerse, a la vista de lo dispuesto en el auto del Tribunal Supremo de 22 de julio de 2021, cuyo contenido se expone a continuación.

\section{Doctrina del Tribunal Supremo en el auto de 22 de julio de 2021 sobre el carácter prescriptible de la acción de restitución de prestaciones}

En el auto de 22 de julio de 2021, de planteamiento de la cuestión prejudicial, el Tribunal Supremo se pronuncia expresamente sobre la posible prescripción de la acción de restitución. Y lo hace para confirmar que la acción sí prescribe. Los apartados 7 a 9 del Fundamento Jurídico 4 tienen la siguiente redacción:

"7.- Por el contrario, apenas se ha planteado ante este Tribunal la cuestión de la prescripción de la acción de restitución de las cosas entregadas en aplicación del contrato cuya nulidad se ha solicitado en un litigio. Quizás la explicación se encuentre en que antes de la reforma del art. 1964 del Código Civil llevada a cabo por la ley 42/2015, de 5 de octubre, el plazo de prescripción de esta acción era 
de 15 años, por lo que no era fácil, en términos temporales, que el demandado pudiera oponer la prescripción de la acción de restitución.

8. - No obstante, en las pocas ocasiones en que tal cuestión se ha planteado, este Tribunal ha distinguido entre la acción por la que se solicita la nulidad del contrato, que no prescribe en el caso de tratarse de una nulidad absoluta, y la acción de restitución de las cosas y el precio entregados recíprocamente por las partes al ejecutar el contrato nulo, que es una acción de naturaleza personal sometida al plazo de prescripción previsto en el art. 1964 del Código Civil, que antes de octubre de 2015 era de 15 años y en la actualidad es de 5 años.

9. - En efecto, en la sentencia de 27 de febrero de 1964 y en la más reciente sentencia 747/2010, de 30 de diciembre, hemos distinguido entre la acción de declaración de nulidad absoluta del contrato, que hemos considerado imprescriptible, y la acción de restitución de las prestaciones realizadas en ejecución del contrato nulo, a la que hemos aplicado el régimen de prescripción de las acciones personales".

El texto transcrito tiene una enorme importancia, porque el Tribunal Supremo establece con rotundidad que la acción de restitución de cantidades del art. 1303 CC está sometida al plazo de prescripción del art. 1964 CC, adelantando así la respuesta que dará en sentencia a la alegación del prestatario consumidor de que esta acción es imprescriptible. El Tribunal Supremo aclara también que esta doctrina sobre la prescriptibilidad de la restitución de prestaciones a que obliga el art. 1303 CC es igualmente aplicable a la restitución de los gastos indebidamente abonados tras la nulidad de la cláusula de gastos del préstamo hipotecario, aunque el fundamento jurídico de esta devolución no esté en el art. 1303 CC sino en el art. 1896 CC (cobro de lo indebido). El auto del TS lo explica de este modo (ap. 11 del FJ 14a):

"El mismo razonamiento es aplicable, por concurrir una identidad de razón jurídica, a los supuestos en que la restitución no se debe realizar entre las partes contratantes, porque los pagos indebidos se hicieron a un tercero, como sucede en el presente caso, en que los receptores de los pagos indebidos hechos por el consumidor en aplicación de la cláusula abusiva fueron terceros (el notario, el registrador de la propiedad, el gestor) y no la parte causante de la nulidad (el prestamista predisponente de la cláusula), por lo que la acción de restitución ha sido calificada por este Tribunal Supremo como una acción derivada de un cobro de lo indebido, en los términos del antes transcrito artículo 1896 del Código Civil (sentencia 725/2018, de 19 de diciembre)".

La tesis defendida por el Tribunal Supremo es correcta, a mi juicio. Pues lo adecuado es entender que la acción de restitución de cantidades está sometida a plazo de prescripción. Y no existiendo un plazo específico para esta acción, ha de estarse al plazo general de cinto años establecido en el art. 1964.2 CC. Esta es la tesis que ha defendido la doctrina más autorizada; entre otros, DELGADO EQUEVERRÍA y PARRA 
LUCÁN ${ }^{2}$, CARRASCO PERERA ${ }^{3}$, DÍEZ PICAZO ${ }^{4}$, y REGLERO CAMPOS ${ }^{5}$. Y es la interpretación que mejor encaja con nuestro derecho, según el cual todas las acciones o pretensiones está sometidas a plazo de prescripción, salvo que expresamente se declare lo contrario (art. 1830.II CC).

Sin embargo, resulta llamativa la contundencia con que se expresa el auto del Tribunal Supremo. Como ya se ha indicado, la doctrina clásica del TS no era unívoca respecto a la posible prescripción de las pretensiones restitutorias, pues había sentencias en ambos sentidos. El Tribunal Supremo parece ignorar este hecho, pues únicamente menciona las sentencias previas favorables a la prescripción de la acción, citando en ese sentido las sentencias de 27 de febrero de 1964 y 30 de diciembre de 2010.

Sea como fuere, lo cierto es que todos los operadores jurídicos deben saber ya que, según el Tribunal Supremo, la restitución de cantidades provocada por la nulidad del contrato o de una cláusula abusiva sí está sometida al plazo de prescripción del art. 1964 CC. Ya no hay excusas para que estos operadores (en particular, los tribunales de instancia) apliquen esta regla.

\section{La compatibilidad de la prescriptibilidad de la acción de restitución con la jurisprudencia del TJUE}

El ATS del 22 de julio de 2021 analiza si el hecho de que la acción de restitución de cantidades esté sometido a un plazo de prescripción puede implicar una vulneración del derecho de la Unión Europea. A esta cuestión se refiere el apartado 11 del Fundamento Jurídico 40, que establece lo siguiente: "En consecuencia, la aplicación de un plazo de prescripción a la acción de restitución de lo pagado por el consumidor en aplicación de una cláusula abusiva no solo es conforme con el principio de seguridad jurídica, que constituye uno de los principios rectores del Derecho de la UE, sino que además no vulnera el principio de equivalencia".

Esta afirmación del Tribunal Supremo es correcta.

La SSTJUE de 6 de octubre de 2009 (asunto C-40/08) afirma que "la fijación de plazos razonables de carácter preclusivo para recurrir, en interés de la seguridad jurídica, es compatible con el Derecho de la Unión" (ap. 41). Esta misma frase se reproduce después en las SSTJUE de 21 de diciembre de 2016 (asunto C-154/15 y otros, ap. 69), 9 de julio de 2020 (asuntos C-698/18 y C-699/18) y 16 de julio de 2020 (asuntos

\footnotetext{
2 DELGADO EQUEVERRÍA/PARRA LUCÁN, Las nulidades de los contratos, Madrid, Dykinson, 2005, pp. 65, 66 y 95.

${ }^{3}$ Derecho de Contratos, $3^{\mathrm{a}}$ ed., Cizur Menor, Aranzadi, 2021, pp. 735, 738 y ss.

${ }^{4}$ Fundamentos del Derecho Civil Patrimonial, Tomo I, 4 a ed., Madrid, Civitas, 1993, pp. 448.

5 "Comentario al art. 19", en BERCOVITZ RODRÍGUEZ-CANO (Dir.), Comentarios a la Ley de Condiciones Generales de la Contratación, Elcano, Aranzadi, 2000, pp. 566 y 567.
} 
C-224/19 y C-259/19). Ahora bien, para que el plazo de prescripción sea válido es preciso que se cumplan los principios de equivalencia y de efectividad. Como señala la STJUE de 9 de julio de 2020, la validez del plazo de prescripción se hace depender de que "ese plazo no sea menos favorable que el aplicable a recursos similares de carácter interno (principio de equivalencia) y no haga imposible en la práctica o excesivamente difícil el ejercicio de los derechos conferidos por el ordenamiento jurídico de la Unión, en particular por la Directiva 93/13 (principio de efectividad)". La STJUE de 16 de julio de 2020 reproduce esta misma argumentación, añadiendo que ese plazo de prescripción que determine el derecho nacional no es contrario a la Directiva 93/13/CEE "siempre que ni el momento en que el plazo empieza a correr ni su duración hagan imposible en la práctica o excesivamente difícil el ejercicio del derecho del consumidor a solicitar tal restitución". Esta argumentación se repite en la STJUE 16 de julio de 2020. Y la más reciente STJUE de 10 de junio de 2021 (asuntos C-776/19 a C-782/19) insiste en que la existencia "de un plazo de prescripción a las acciones de carácter restitutorio, ejercitadas por unos consumidores con el fin de hacer valer derechos que les confiere la Directiva 93/13, no es, en sí misma, contraria al principio de efectividad, siempre que su aplicación no haga imposible en la práctica o excesivamente difícil el ejercicio de los derechos conferidos en dicha Directiva" (ap. 40).

En consecuencia, es correcto sostener, como hace el auto del TS, la compatibilidad de la prescripción de la acción de restitución con la doctrina del TJUE. Pero lo relevante no es tanto que el plazo de prescripción de esta acción respete el principio de equivalencia (que también), sino que no vulnere el principio de efectividad; esto es, que ese plazo no haga imposible en la práctica o excesivamente difícil el ejercicio de los derechos por el consumidor. Hubiera sido adecuado que el TS se hubiera referido también a este principio de efectividad.

\section{La aplicación de la doctrina al crédito revolving usurario: la imposibilidad de seguir manteniendo que no prescribe la acción de restitución de los intereses usurarios abonados}

La doctrina sentada por el auto del Tribunal Supremo (la acción de restitución de prestaciones tras la nulidad está sometida al plazo de prescripción del art. 1964 CC) se aplica a cualquier hipótesis de nulidad absoluta o de pleno derecho.

Se aplica, por tanto, a la acción de restitución de cantidades derivada de la nulidad de una cláusula predispuesta que no supera el control de incorporación o que es abusiva. En consecuencia, son contrarias al ATS de 22 de julio de 2021 las sentencias que defienden que no prescribe la acción de restitución de los gastos hipotecarios. Esta tesis de la imprescriptibilidad de la acción restitutoria de los gastos ha sido acogida, entre otras, por las SSAP Pontevedra de 15 de marzo de 2017, Albacete de 21 de noviembre de 2019 (JUR 2020, 38924), Guipúzcoa de 11 de enero de 2021 
(JUR 137808), Segovia de 27 de junio de 2019 (JUR 266042), Valladolid de 10 de diciembre de 2019 (JUR 88552), y León de 31 de julio de 2020 (JUR 272955).

La regla de la prescripción de la acción de restitución ha de regir también para las pretensiones de restitución de intereses remuneratorios abonados en caso de nulidad de un préstamo usurarios. Por eso, son contrarias al ATS de 22 de julio de 2021 las sentencias que entienden que la acción de restitución de estos intereses remuneratorios no prescribe.

Un primer ejemplo de este grupo de sentencias lo constituye la SAP Málaga (Secc. 7) 48/2021, de 14 de julio (ECLI:ES:APML:2021:110). La sentencia de primera instancia declara la nulidad del contrato de tarjeta de crédito celebrado en 1997, y condena a restituir los intereses abonados a partir del 17 de abril de 2005. Frente a ella recurre en apelación el prestatario, solicitando, entre otras cosas, que la restitución debe predicarse de todos los intereses abonados desde el momento de la celebración del contrato. La Audiencia Provincial acepta esta petición, y recova la sentencia de instancia en ese punto. Sostiene la Audiencia que la distinción que hace el juez de primera instancia entre la acción de nulidad (que no prescribe) y la acción de restitución (que sí prescribe) tiene su base en distintos pronunciamientos judiciales sobre la cláusula de gastos hipotecarios. Pero que esta doctrina no puede trasladarse a un supuesto de nulidad por usura, pues en este caso la nulidad lleva consigo la consiguiente obligación de restitución, por imposición del art. 3 de la Ley de Represión de la Usura. Así resulta de la STS 539/2009, de 14 de julio, que sanciona la nulidad del contrato, "con la consiguiente obligación o deber de restitución". De esta frase de la STS deduce la Audiencia que la restitución ha de proceder siempre y en todo caso. Por eso concluye que "declarada la nulidad del contrato, no cabe fijar límite temporal a la restitución en función del tiempo transcurrido desde que aquél fue firmado, lo que parece más acorde con los términos en que se pronuncia el tribunal supremo en la citada sentencia no 539/2009, de 14 de julio".

La argumentación de la AP Málaga es desafortunada. El art. 3 LRU no contempla una suerte de devolución automática de cantidades tras la nulidad del préstamo usurario. Se limita a declarar que una vez decretada la nulidad del crédito (en este caso, revolving), el prestatario tiene derecho a obtener del prestamista la restitución de los intereses remuneratorios y las comisiones que ha abonado. Pero este derecho a la devolución de cantidades que tiene el prestatario está sometido al plazo de prescripción del art. 1964 CC, como ahora establece el ATS de 22 de julio de 2021. Tampoco puede defenderse, como hace la SAP Málaga, que la acción restitutoria de gastos hipotecarios sí prescribe, pero no la restitutoria tras la nulidad por usura. Pues el propio ATS citado señala que la acción restitutoria prescribe sea cual sea el tipo de nulidad absoluta, ya se trata de la nulidad de un contrato (por cualquier circunstancia) o de una cláusula abusiva.

En parecidos términos se expresa la SAP Madrid (Secc. 25) 458/2020, de 19 de noviembre (JUR 2021, 28686). La sentencia, después de citar el art. 3 LRU, señala 
que "la previsión legal descrita concreta el efecto de declaración de nulidad radical atribuida al carácter usurario de los intereses, con la obligación del prestamista de devolver al prestatario el total de lo percibido que exceda del capital prestado, efecto de devolución total implícito en la declaración de nulidad radical que no permite a criterio de esta Sección, en el presente caso y con esos presupuestos, nulidad radical y extensión de efectos definida en norma especial, apreciar la existencia de plazo de prescripción distinto respecto de la exigibilidad de aplicación de los efectos de la declaración de nulidad, validación de efectos nulos por el transcurso del tiempo incompatible con el tenor literal de la norma que exige tener en cuenta el total de lo percibido por la prestamista (RJ 60; el subrayado es mío, y no de la sentencia)". En consecuencia, la sentencia establece que, al igual que la acción declarativa de nulidad, la acción de restitución tampoco está sometida a plazo de prescripción. Tesis hoy insostenible, a la luz del ATS de 22 de julio de 2021.

La SJPI no 20 de Zaragoza 201/2021, de 14 de julio, también considera imprescriptible la acción de restitución de intereses usurarios. La sentencia declara la nulidad del crédito revolving, por haberse fijado unos intereses usurarios. Y frente a la alegación de la parte prestamista de que la acción de restitución ha prescrito, la sentencia establece que "siendo las consecuencias de dicha nulidad las previstas en el art. 3 de la Ley de Represión de la Usura, esto es, el prestatario estará obligado a entregar tan sólo la suma recibida, lo que en modo alguno puede entenderse prescrito, dado que se trata de un efecto legal de la nulidad del contrato por usura".

De nuevo se parte de la premisa (equivocada) de que la liquidación del crédito revolving usurario es un efecto legal impuesto por el art. 3 LRU, de manera que ha de procederse del modo expuesto en este precepto, al margen de cualquier consideración temporal. Y eso es un error notorio, pues la acción de restitución de cantidades está sometida al plazo de prescripción, como cualquier acción restitutoria derivada de la nulidad de un contrato.

Mención especial merece la SJPIeI no 5 de Ferrol 332/2021, de 29 de julio. También aquí la entidad de crédito opone la excepción de prescripción de la acción de intereses usurarios abonados. Sobre el particular, la sentencia declara lo siguiente: "No cabe acoger las alegaciones realizadas por la parte demandada, en el sentido de que la acción declarativa de nulidad (ya sea con base en la usura o en la falta de transparencia) y la de restitución de las prestaciones indebidamente satisfechas son independientes a efectos de prescripción, por lo que en el presente caso, al haberse formulado la reclamación extrajudicial, interruptiva de la prescripción, en fecha 18 de febrero de 2021, los intereses remuneratorios pagados por el actor con anterioridad al 18 de febrero de 2016 estarían prescritos, al ser aplicable el plazo de prescripción de cinco años que establece el artículo 1.964-2 del Código Civil y, en consecuencia, no resultaría procedente su devolución. Debe tenerse en cuenta que las consecuencias de la declaración de nulidad de un contrato por su carácter usurario aparecen previstas en la propia Ley de Represión de la Usura. En efecto, el artículo 3 de la citada ley señala que "Declarada con arreglo a esta ley la nulidad de un 
contrato, el prestatario estará obligado a entregar tan sólo la suma recibida; y si hubiera satisfecho parte de aquélla y los intereses vencidos, el prestamista devolverá al prestatario lo que, tomando en cuenta el total de lo percibido, exceda del capital prestado". Y concluye así: "Por tanto, la restitución dineraria es consecuencia directa de la declaración de nulidad del contrato, sin que quepa hablar de dos acciones independientes, una imprescriptible y la otra sometida al plazo de prescripción de cinco años".

La sentencia no respeta la doctrina del auto del TS. Contradice este auto cuando señala que no hay dos acciones independientes (acción declarativa de nulidad y restitución), sino una única, que es imprescriptible, por ser la restitución una "consecuencia directa" de la nulidad.

La SJPIeI no 1 de Piloña no 135/2021, de 29 de julio, hace un razonamiento similar. Frente a la alegación de prescripción de la entidad prestamista demandada, señala que "la acción de nulidad es imprescriptible, no se trata de dos acciones acumuladas, la reclamación de cantidad es la consecuencia de la nulidad pretendida que es el objeto primordial del litigio, sino hay nulidad no hay condena al pago de cantidad alguna, siendo imprescriptible dicha acción de nulidad". Aunque la redacción es bastante mejorable, establece que solo se ejercita una acción, que es imprescriptible, y que la estimación de la demanda (nulidad del crédito revolving) supone necesariamente la devolución de los intereses usurarios. Ya se ha insistido en que esta forma de entender las cosas es contraria al ATS de 22 de julio de 2021.

En la SJPIeI no de de Lalín no 167/2021, de 30 de julio, el prestamista demandado había opuesto la excepción de prescripción, considerando que solo debía restituir los intereses usurarios satisfechos y no prescritos. Frente a ello, la sentencia se limita a reproducir las sentencias del Tribunal Supremo que declaran que la nulidad absoluta del préstamo usurario no es susceptible de prescripción. Con este simple argumento, y sin percatarse de que la imprescriptibilidad a la que alude el alto tribunal es únicamente la de la acción declarativa, el juzgado de instancia desestima la excepción de prescripción.

La SJPI no 2 de Pamplona no 202/2021, de 27 de julio incide en esta misma (equivocada) idea. No se trata de dos acciones distintas, sino que se ejercita una única acción, la de nulidad, que trae como consecuencia la devolución de los intereses usurarios. Y esa única acción ha sido considerada como imprescriptible por el Tribunal Supremo. Por eso la excepción de prescripción no puede prosperar.

Por último, la SJPI no 5 de San Bartolomé de Tirajana no 258/2021, de 30 de julio, constituye un compendio de todos los (inconsistentes) argumentos en favor de la imprescriptibilidad de la acción de restitución de intereses usurarios. El Fundamento Jurídico 4 ("Posible prescripción de la acción de restitución de cantidades. Desestimación") establece lo siguiente: 
"El artículo 3 de la Ley sobre Represión de la Usura de 23 de julio de 1908 establece que "declarada con arreglo a esta ley la nulidad de un contrato, el prestatario estará obligado a entregar tan solo la suma recibida; y si hubiera satisfecho parte de aquélla y los intereses vencidos, el prestamista devolverá al prestatario lo que, tomando en cuenta el total de lo percibido, exceda del capital prestado", precepto que se ha de poner en relación con el artículo 6.3 del Código Civil en cuanto establece que "los actos contrarios a las normas imperativas y a las prohibitivas son nulos de pleno derecho, salvo que en ellas se establezca un efecto distinto para el caso de contravención" , como es en este caso la fijación legal de la obligación del prestatario de devolver la suma realmente recibida.

En consecuencia, la declaración de nulidad del contrato de préstamo usurario produce como efecto fundamental el de que el prestatario está obligado a entregar tan solo lo recibido de tal modo que queda dispensado de pagar cualquier clase de intereses, usurarios o legítimos.

Lo anterior conduce necesariamente a la desestimación de la prescripción planteada. La nulidad del préstamo usurario, claramente establecida por el artículo 1 de la Ley de 23 de julio de 1908, comporta una ineficacia del negocio que es radical, absoluta y originaria, que no admite convalidación confirmatoria, porque es fatalmente insanable, ni es susceptible de prescripción extintiva. Dicha nulidad afecta a la totalidad del convenio con la única consecuencia, establecida en el artículo 3, de que ha de retrotraerse la situación al momento inmediatamente anterior al préstamo, lo que determina que el prestatario haya de devolver la cantidad efectivamente recibida sin que para ello haya de tenerse en cuenta plazo alguno establecido para tal devolución, ya que su fijación queda comprendida en la ineficacia absoluta y total de lo convenido.

Por tanto, la solución que debe adoptarse es la que mejor se acomoda al espíritu y finalidad de la Ley de Usura, aquí aplicada. Son precisamente los efectos previstos en la Ley de Usura los que se han invocado, se han estudiado, y se consideran procedentes.

Contrariamente a lo que parece deducirse de lo expuesto por la demandada, debe excluirse la aplicación de efectos del art. 1303 CC a la nulidad declarada por ser de aplicación preferente çlos efectos establecidos en el art. 3 de la norma especial de Represión de la Usura, que concreta los efectos de la nulidad del contrato al establecer " Declarada con arreglo a esta ley la nulidad de un contrato, el prestatario estará obligado a entregar tan sólo la suma recibida; y si hubiera satisfecho parte de aquélla y los intereses vencidos, el prestamista devolverá al prestatario lo que, tomando en cuenta el total de lo percibido, exceda del capital prestado", motivo por el que la declaración de nulidad en el presente caso lleva a declarar la obligación de la demandante de entregar las cantidades recibidas de la demandada con motivo del contrato, con obligación de la demandada de 
devolver al demandante todas las cantidades recibidas que excedan del capital prestado, a determinar en ejecución de Sentencia.

La previsión legal descrita concreta el efecto de declaración de nulidad radical atribuida al carácter usurario de los intereses, con la obligación del prestamista de devolver al prestatario el total de lo percibido que exceda del capital prestado, efecto de devolución total implícito en la declaración de nulidad radical que no permite a criterio de este juzgador, en el presente caso y con esos presupuestos, nulidad radical y extensión de efectos definida en norma especial, apreciar la existencia de plazo de prescripción distinto respecto de la exigibilidad de aplicación de los efectos de la declaración de nulidad, validación de efectos nulos por el transcurso del tiempo incompatible con el tenor literal de la norma que exige tener en cuenta el total de lo percibido por la prestamista".

Concluyo repitiendo lo que ha he señalado en varias ocasiones: estos argumentos son incorrectos y contrarios a la doctrina sentada por el ATS de 22 de julio de 2021, según la cual la acción de restitución de cantidades (intereses remuneratorios abusivos) sí prescribe.

\section{EI "dies a quo" de la acción de restitución de los gastos hipotecarios en las cuestiones prejudiciales.}

Las dos cuestiones prejudiciales solicitan que se aclare cuál es el "dies a quo" del plazo de prescripción de la acción de restitución de los gastos hipotecarios.

Como con detalle he explicado en otro lugar", para fijar el "dies a quo" ha de estarse al art. 1969 CC. Según este precepto, el plazo prescriptivo de las acciones de restitución de los gastos indebidamente abonados empieza a correr "desde el día en que pudieron ejercitarse". Una adecuada interpretación de este precepto obliga a entender que para que el plazo de prescripción comience a correr deben concurrir tres requisitos: (i) que exista la posibilidad jurídica de ejercitar la pretensión, esto es, que la pretensión haya nacido y sea jurídicamente ejercitable; (ii) que el acreedor conozca, o debiera haber conocido si hubiera con la diligencia debida, los hechos que fundamentan su pretensión y la identidad de la persona contra la que reclamar; y (iii) que el acreedor tenga la posibilidad real y efectiva de ejercitar la pretensión, esto es, que no concurra una circunstancia (fuerza mayor) que le impida reclamar.

En relación con la cláusula de gastos, hay que entender que la acción de devolución de los gastos indebidamente abonados ha nacido y es jurídicamente ejercitable el día en que el prestatario abonó esos gastos cuya devolución solicita. No puede fijarse en una fecha anterior (por ejemplo, al de celebración del contrato), pues si no ha pagado

\footnotetext{
6 "La prescripción de la acción de restitución de cantidades tras la nulidad de un crédito revolving usurario", Revista CESCO de Derecho de Consumo, 2021, n 38, pp. 67 y ss.
} 
esas cantidades, no puede pedir su restitución. Únicamente desde su abono tiene el consumidor la posibilidad jurídica de ejercitar la acción de restitución.

Pero para que el plazo prescriptivo empiece a correr se exige, en segundo lugar, que el consumidor conozca, o haya podido conocer de haber actuado con la diligencia exigible, los hechos que fundamentan la pretensión de restitución y la identidad de la persona contra la que reclamar. Sin tomar en consideración la doctrina del TJUE, del art. 1969 CC resulta que los hechos que fundamentan la pretensión son tres: que se ha celebrado un contrato de préstamo hipotecario, que ese contrato impone al prestatario el abono de todos los gastos derivados de su preparación y perfección, y que el prestatario ha pagado estos gastos. El conocimiento sobre los dos primeros hechos no plantea dificultades. En cuanto al tercero, el prestatario conoce que se han abonado cuando la gestoría le remite la documentación con todas las facturas del notario, registro y de la propia gestoría, y el documento acreditativo de haber pagado el IAJD. Esta es la fecha relevante a efectos del dies a quo. El conocimiento requerido ha de ser sobre los hechos, y no sobre el derecho. Por eso es irrelevante, a efectos de fijar el dies a quo conforme al art. 1969 CC, si el consumidor conoce, o podía conocer, que la cláusula de gastos es abusiva y nula, y que por eso tenía derecho a solicitar la devolución de los gastos indebidamente abonados.

El régimen expuesto es el que deriva del Código Civil y la jurisprudencia que aplica el art. 1969 CC. Sin embargo, el TJUE ha dictado algunas sentencias que pueden suponer una modificación de esta tesis. Se trata de las SSTJUE de 9 de julio de 2020 (asuntos C-698/18 y C-699/18), 16 de julio de 2020, asuntos C-244/19 y C-259/19), 22 de abril de 2021 (asunto C-485/19). Entiende el TJUE que cada Estado puede fijar plazos de prescripción, que son conformes al derecho comunitario si respetan los principios de equivalencia y de efectividad. En principio, un plazo de prescripción de cinco años respeta el principio de efectividad, pues no parece que pueda hacer difícil en la práctica o excesivamente difícil el ejercicio de la acción de restitución de cantidades. Pero ello dependerá de cuándo empiece a correr el plazo de prescripción. En esta línea, el TJUE establece que el consumidor ha de poder tener conocimiento del carácter abusivo de la cláusula. De donde resulta que es contrario al derecho comunitario que se considere prescrita una acción de restitución de cantidades si transcurre el plazo de prescripción y el consumidor no ha podido tener conocimiento del carácter abusivo de la cláusula.

En otro lugar ya he indicado cuál es el verdadero significado de estas sentencias del TJUE7. Cuando en ellas se establece que puede ser contrario al principio de efectividad fijar como dies a quo el momento de la celebración del contrato, de la producción del enriquecimiento o del cumplimiento íntegro del contrato, lo hace porque, contado desde ese instante, puede haber transcurrido el plazo prescriptivo sin que el consumidor haya podido conocer el carácter abusivo la cláusula. Pero es importante destacar que el TJUE no indica cuál ha de ser el día del inicio del cómputo del plazo

\footnotetext{
${ }^{7}$ En “La prescripción de la acción...”, cit., pp. 77 y ss.
} 
prescriptivo, ni exige que ese día el consumidor conozca o haya podido conocer el carácter abusivo o ilícito de la cláusula. Esta era la interpretación adecuada de la doctrina comunitaria hasta la STJUE de 10 de junio de 2021 (asuntos C-776/19 a C-782/19). Esta sentencia parece adoptar otra tesis. Pues en su apartado 48 parece indicar que la fecha de celebración del contrato no puede fijarse como dies a quo porque el consumidor podía ignorar, en ese momento, los derechos que le reconoce la Directiva de cláusulas abusivas.

En definitiva, de la doctrina del TJUE, y en particular de la última sentencia citada, no resulta claro si el conocimiento (real o potencial) por el consumidor del carácter abusivo de la cláusula es un requisito para que empiece a correr el plazo prescriptivo, o basta con que antes de que finalice el plazo prescriptivo el consumidor conozca (o haya podido conocer) que la cláusula es abusiva y que eso le permitía reclamar. Tampoco aclara el TJUE en qué casos un consumidor tiene conocimiento de esa circunstancia, y sobre todo cuándo un consumidor medio puede haber tenido conocimiento de este hecho.

Por estas razones considero justificada la solicitud de una cuestión prejudicial al TJUE. Pero resulta llamativo el modo en que lo ha hecho el Tribunal Supremo en su auto de 22 de julio de 2021.

En primer lugar, llama la atención que el auto parta de la tesis de que, según el TJUE, es un requisito para que se inicie el cómputo del plazo de prescripción que el consumidor conozca el carácter abusivo de la cláusula. Es cierto que así parece indicarlo la STJUE de 10 de junio de 2021 en su apartado 48 (fallo). Pero los apartados anteriores seguían la tesis "clásica" del TJUE, y por eso no queda claro si realmente el TJUE ha querido vincular el dies a quo al conocimiento potencial por el consumidor del carácter abusivo de la cláusula. En segundo lugar, se echa en falta una referencia expresa al conocimiento (real o potencial) por el consumidor del carácter abusivo de la cláusula; pues es este el elemento central que ha de tomarse en consideración para acoger una interpretación del art. 1969 CC que sea compatible con el derecho comunitario. En tercer lugar, no se comprende por qué se descarta definitivamente como dies a quo el día en que el consumidor ha abonado los gastos indebidos; puesto que es posible que ese día el consumidor conozca (o pudiera haber conocido) el carácter abusivo de la cláusula (por ejemplo, en un préstamo celebrado en febrero de 2019 quizás cabe sostener que un consumidor medio ya puede conocer el carácter abusivo de la cláusula, al haberse dictado las SSTS de 23 de diciembre de 2015 y las de 23 de enero de 2019).

Pero lo que realmente resulta sorprendente es el elenco de preguntas concretas (tres) que se formulan y el modo jerárquico en que se plantean.

La primera pregunta es si es conforme a las normas comunitarias fijar como inicio del plazo prescriptivo de la acción restitutoria de gastos el día en que es firme la sentencia que declara la nulidad de la cláusula. A mí me parece claro que establecer 
el dies a quo de ese modo es conforme al derecho comunitario. Pero lo llamativo es que, si el TJUE responde declarando que es conforme, no tenga ya que responder a las preguntas segunda y tercera. Pues la segunda pregunta solamente ha de responderla si la primera pregunta tiene una respuesta negativa. $Y$ lo mismo sucede con la tercera pregunta. Hubiera sido más adecuado solicitar al TJUE que respondiera en todo caso a las tres preguntas, y no hacerlo depender de la respuesta dada a la pregunta anterior. Además, dado el modo (jerarquizado) en que se formulan, y pues que si se responde afirmativamente a la primera pregunta ya no tendrá que pronunciarse sobre las otras dos, puede anticiparse que, si efectivamente el TJUE responde afirmativamente a la primera cuestión, el Tribunal Supremo sancionará que el dies a quo es la fecha de la firmeza de la sentencia en que se declara la nulidad de la cláusula. Insisto que esta interpretación es conforme al derecho comunitario y a la doctrina del TJUE, pero no estoy convencido de que resulte la más apropiada tomando en consideración el art. 1969 CC.

Por otra parte, en la pregunta dos se plantea si es conforme al derecho comunitario fijar como dies a quo el 23 de enero de 2019. ¿Y por qué no el 23 de diciembre de 2015, que es la fecha de la primera sentencia del Tribunal Supremo que considera abusiva la cláusula de gastos? Repárese en que parece buscarse un hecho a partir del cual se permita a un consumidor medio, razonablemente atento y perspicaz, ser conocedor del carácter abusivo de una cláusula. Si ese hecho es la publicación de una sentencia del Tribunal Supremo, parece más oportuno vincularlo a la primera sentencia que declara la nulidad de la cláusula (en el caso de los gastos, la de 23 de diciembre de 2015), y no otras sentencias posteriores que se ocupan de señalar qué concretas cantidades puede reclamar el consumidor. Porque lo que el TJUE exige es que el consumidor conozca o pueda conocer el carácter abusivo de la cláusula, y no las cuantías concretas que puede reclamar tras esa nulidad.

Tampoco alcanzo a comprender la tercera pregunta. En ella se plantea si es conforme a las normas comunitarias entender que el plazo prescriptivo comienza el día en que el TJUE establece que la acción de restitución puede estar sujeta a prescripción (lo hace en las SSTJUE de 9 de julio de 2020 y 16 de julio de 2020). A efectos del fijar el dies a quo es irrelevante si el consumidor conoce (o no) que la acción de restitución está sometida a plazo de prescripción. Es sorprendente esta pregunta, pues la única circunstancia jurídica que el consumidor debe conocer, según la doctrina del TJUE, es el carácter abusivo de la cláusula.

Las "debilidades" de la cuestión prejudicial planteada por el TS han sido "subsanadas" por la cuestión prejudicial del JPI no 20 de Barcelona. En el apartado II. 2 de este trabajo se ha expuesto el argumentario empleado por el Juzgado de Barcelona, y las tres concretas preguntas que formula al TJUE. Resultan muy interesante las reflexiones contenidas en el auto en relación con el "agotamiento" de los efectos de la cláusula de gastos tan pronto el consumidor los abona, lo que sucede en el momento de celebración del contrato. Este hecho puede ser relevante, pues desde que el consumidor abona esos gastos es consciente de cómo la cláusula de gastos 
afecta a su patrimonio, y del perjuicio económico que le supone. Lo cual puede ser importante para averiguar cuándo el consumidor conoce el carácter abusivo de la cláusula, que es el elemento decisivo para determinar si la fijación de ese "dies a quo" es contrario al principio de efectividad.

El auto de Barcelona formula tres preguntas concretas. Las tres preguntas son pertinentes, y no están jerarquizadas (a diferencia del auto del TS), lo que obligará al TJUE a pronunciarse sobre cada una de ellas.

El auto de Barcelona parte de que es compatible con el derecho europeo fijar el "dies a quo" de la acción de restitución el día en que se declara nula la cláusula por sentencia. Pero se cuestiona ( $y$ esa es la primera pregunta que formula) si puede fijarse el "dies a quo" antes de que la cláusula sea declarada nula. Creo que el TJUE responderá de forma afirmativa, pues el consumidor puede tener conocimiento del carácter abusivo de la cláusula por otras vías.

La segunda pregunta es si es compatible con el derecho europeo fijar como inicio del plazo de prescripción de la acción de restitución el día en que el Tribunal Supremo (que es el tribunal con capacidad para dictar jurisprudencia) dicte sentencia en la que declara abusiva la cláusula en cuestión, porque puede entenderse que un consumidor medio puede conocer esta sentencia. En materia de gastos, esa sentencia es la STS de 23 de diciembre de 2015. A mi juicio, el TJUE debe responder de forma afirmativa, porque parece claro que un consumidor puede conocer desde ese día que la cláusula en cuestión es abusiva, por haberlo así establecido el tribunal encargado de crear jurisprudencia en nuestro ordenamiento jurídico y ser las sentencias del tribunal supremo fácilmente accesibles.

La tercera y última pregunta se refiere a la compatibilidad con el derecho europeo de fijar como "dies a quo" el día en que el consumidor abonó los gastos, pues en ese instante la cláusula de gastos agota sus efectos y el consumidor es consciente del perjuicio económico que le irroga.

Como ya se ha señalado, se trata de una materia compleja. Habrá que esperar a que el TJUE resuelva las dos cuestiones prejudiciales (se supone que lo hará de forma conjunta), y que la sentencia sea lo suficientemente clara y comprensible como para que el Tribunal Supremo dicte una doctrina que permita poner fin a esta controversia jurídica.

\section{Intrascendencia de las cuestiones prejudiciales para fijar el "dies a quo" de la acción de restitución de cantidades en el crédito revolving nulo}

La sentencia que dicte el TJUE dando respuesta a las dos cuestiones prejudiciales planteadas por el Tribunal Supremo y el JPI no 20 de Barcelona son absolutamente irrelevantes para fijar el inicio del plazo de prescripción de la acción de restitución de 
los intereses remuneratorios abonados por el prestatario en caso de crédito revolving nulo por usurario.

Una adecuada aplicación del art. 1969 CC permite entender que en el préstamo usurario la acción de restitución de intereses remuneratorios satisfechos ha nacido y es jurídicamente ejercitable por el prestatario el día en que el prestatario abonó esos intereses. Y que los hechos que fundamentan la pretensión del prestatario (que este debe conocer para que empiece a correr el plazo prescriptivo) son los siguientes: que él (el prestatario) ha celebrado un contrato de crédito, que ese contrato impone al prestatario el abono de intereses remuneratorios sobre el capital dispuesto, y que esos intereses remuneratorios los va pagando el prestatario mensualmente cuando satisface las cuotas de amortización. Es obvio que el prestatario conoce estos tres hechos. Estas tres circunstancias las conoce el prestatario cada vez que mensualmente abona intereses remuneratorios. Ya he expuesto en otro lugar las razones por las que la aplicación del art. 1969 CC conduce a fijar el "dies a quo" del plazo prescriptivo en ese momento ${ }^{8}$. Y cómo no cabe vincular el inicio del plazo de prescripción a que el prestatario conozca (o hubiera debido conocer, de haber actuado con la diligencia debida) el carácter usurario del préstamo y que por esa razón él tenía derecho a solicitar la nulidad del préstamo y a solicitar la restitución de los intereses remuneratorios satisfechos ${ }^{9}$.

Pues bien, sea cual sea la decisión que adopte el TJUE, ello no afectará a la forma de fijar el "dies a quo" que se ha expuesto. Ello se debe a que la Ley de Represión de la Usura no persigue incorporar al derecho español ninguna Directiva europea y por esa razón no puede ser contraria al derecho europeo y, en particular, al principio de efectividad diseñado por el TJUE.

En esta línea, el TJUE ha establecido que la Ley de Represión de la Usura no puede vulnerar la legislación europea de protección de consumidores. Lo ha hecho en el ATJUE de 25 de marzo de 2021 (asunto C-503/20), que resuelve la cuestión prejudicial planteada por la AP Las Palmas mediante auto de 14 de septiembre de 2020 (ECLI:ES:APGC:2020:111A). En este auto el TJUE sanciona que una ley nacional que establece límites máximos a los intereses remuneratorios (como la LRU) no es contraria a las Directivas de crédito al consumo (Directivas 87/102/CEE y 2008/48/UE). La fijación de límites máximos a los préstamos concedidos a los consumidores es una materia no armonizada, por lo que se rige exclusivamente por el derecho nacional.

Esta doctrina ha sido confirmada por el Tribunal Supremo. En la STS 40/2021, de 2 de febrero (ECLI:ES:TS:2021:266), se discute si en un pleito sobre nulidad de una tarjeta de crédito revolving puede aplicarse la doctrina jurisprudencial del TS dictada en litigios sobre cláusulas abusivas según la cual hay que condenar en costas al

\footnotetext{
${ }^{8}$ En "La prescripción de la acción...", cit., pp. 73 y ss.

${ }^{9}$ En "La prescripción de la acción...", cit., pp. 74 y ss.
} 
prestamista demandado si es abusiva y nula la cláusula predispuesta, aunque existan serias dudas de hecho o de derecho o aunque se condene a abonar al consumidor una cantidad inferior a la reclamada en la demanda. En la sentencia mencionada el TS responde que no puede aplicarse esa doctrina a un préstamo usurario. Como el propio tribunal indica, la doctrina jurisprudencial citada se apoya en la jurisprudencia del TJUE, que obliga a los jueces de los Estados miembros a inaplicar una norma de Derecho interno (en este caso, el art. 394.1 LEC, que permite no imponer las costas al que pierde el pleito si hay dudas de hecho o de derecho) cuando la considere contraria al Derecho de la UE. Esta es una exigencia derivada de los arts. 6.1 y 7.1 de la Directiva 93/13/CEE y del principio de efectividad del derecho de la UE. La STS 40/2021 establece que "cuando la cuestión litigiosa no está regulada por el Derecho de la UE y, por consiguiente, no entra en juego el principio de primacía de este Derecho, el juez no puede dejar de aplicar ninguna norma legal nacional (en este caso, el art. 394.1 de la Ley de Enjuiciamiento Civil)". Y añade que en el caso de autos la acción ejercitada está basada exclusivamente en la Ley de Represión de la Usura, y no guarda relación alguna con el Derecho de la Unión Europea. Por esa razón no procede aplicar la doctrina del TJUE y del TS sobre el respeto del principio de efectividad en materia de imposición de costas.

La conclusión es que no procede aplicar el principio de efectividad a un préstamo usurario. Ello tiene consecuencias en materia de costas, y también en relación con la fijación del "dies a quo" del plazo prescriptivo de la acción de restitución de los intereses remuneratorios usurarios. Como no se aplica la doctrina del TJUE sobre el principio de efectividad, es intrascendente para el crédito usurario la respuesta del TJUE a las dos cuestiones prejudiciales analizadas. La forma en que el TJUE responda a las cuestiones prejudiciales tendrá importancia, evidentemente, en materia de cláusulas abusivas en contratos con consumidores, pero no para los supuestos de nulidad de préstamos por usura.

\section{Bibliografía}

CARrasco PererA, A., Derecho de Contratos, 3a ed., Cizur Menor, Aranzadi, 2021.

DELGADO EQUEVERRÍA, J./PARRA LUCÁN, M. A., Las nulidades de los contratos, Madrid, Dykinson, 2005.

DÍEZ-PICAZO, L., Fundamentos del Derecho Civil Patrimonial, Tomo I, $4^{a}$ ed., Madrid, Civitas, 1993.

MARÍN LÓPEZ, M. J., "Cuestiones pendientes sobre la cláusula de gastos de los préstamos hipotecarios", en ÁLVAREZ LATA/PEÑA LÓPEZ, Mecanismos de protección del consumidor de productos y servicios financieros, Cizur Menor, Thomson Reuters, 2021, pp. 141 y ss. 
MARÍN LÓPEZ, M. J., "La prescripción de la acción de restitución de cantidades tras la nulidad de un crédito revolving usurario", Revista CESCO de Derecho de Consumo, 2021 , no 38 , pp. 56 y ss.

REGLERO CAMPOS, F., "Comentario al art. 19", en BERCOVITZ RODRÍGUEZ-CANO (Dir.), Comentarios a la Ley de Condiciones Generales de la Contratación, Elcano, Aranzadi, 2000, pp. 566 y ss. 